\title{
MONITORING THE UPTAKE AND INTRACELLULAR FATE OF NANOVECTORS BY MICROSCOPICAL TECHNIQUES
}

\author{
MANUELA COSTANZO, FLAVIA CARTON, MANUELA MALATESTA (*)
}

SUNTO. - I nanovettori rivestono grande interesse per le loro potenzialità in campo terapeutico e diagnostico, come sistemi per veicolare farmaci e per l'imaging medicale. Le loro particolari caratteristiche ne consentono il passaggio attraverso le barriere biologiche e l'accumulo nei siti bersaglio, garantendo inoltre la protezione delle molecole caricate e la modulazione del loro rilascio. Per somministrare nanovettori in maniera efficace e sicura è ovviamente necessario valutarne il possibile effetto citotossico, ma è anche essenziale chiarire i meccanismi di internalizzazione, il traffico intracellulare, le relazioni con gli organuli e la persistenza all'interno della cellula dei nanoparticolati, con particolare attenzione alle loro vie degradative. La microscopia è particolarmente idonea per descrivere le interazioni dei nanovettori con la membrana cellulare e il loro destino intracellulare dopo l'internalizzazione. Nanoparticelle legate a fluorocromi possono essere osservate in microscopia a fluorescenza convenzionale e confocale, mentre l'elevata risoluzione della microscopia elettronica a trasmissione consente di rivelare le fini relazioni dei nanovettori con le strutture subcellulari. In questo articolo sono riassunti alcuni studi condotti utilizzando tecniche microscopiche per valutare le proprietà di nanoparticelle destinate a scopi terapeutici e diagnostici.

ABSTRACT. - Nanovectors are receiving great attention for their potential in therapeutic and diagnostic applications as innovative systems for drug delivery and medical imaging. Their unique features allow them to pass through the biological barriers, to accumulate at the target sites, to protect the loaded drugs from enzymatic degradation and to modulate their release. To design effective and safe administration procedures of nanovectors it is obviously mandatory to assess their possible cytotoxicity, but it is also essential to elucidate the uptake mechanism(s), the intracellular trafficking pathway, the interactions with cell organelles and the intracellular persistence of nanovectors, paying

${ }^{* *}$ Department of Neuroscience, Biomedicine and Movement, Anatomy and Histology Section, University of Verona, Italy. E-mail: manuela.malatesta@univr.it 
particular attention to their degradation routes. Microscopy is especially suitable to describe the interaction of nanocarriers with the cell surface and their intracellular fate following internalization. Fluorochrome-labelled nanoparticles may be observed by conventional and confocal fluorescence microscopy, while the higher resolution of transmission electron microscopy allows to reveal the specific relationships of nanocomposites with the subcellular constituents. This work summarizes some studies performed by different microscopical techniques to evaluate the properties of nanoparticles intended for therapeutic and diagnostic purposes.

\section{INTRODUCTION}

Nanovectors are receiving great attention for their potential in therapeutic and diagnostic applications as innovative drug delivery and medical imaging systems. Their unique properties (e.g. small size, large and functionalizable surface area) allow them to pass through the biological barriers (cell membrane, capillary wall, blood brain barrier) and to accumulate at the target sites. Moreover, nanovectors may protect the loaded molecules from enzymatic degradation, prolonging their permanence in the living organism; in addition, the release of the loaded drugs may be modulated, thus improving their sustainability and availability.

Biocompatibility and biodegradability are the basic features of nanovectors designed for biomedical use; it is therefore mandatory to test the behavior of nanovectors in the biological environment. Although nanovectors are intended for administration in vivo, the first step of their evaluation is generally performed in in vitro systems. Evaluating the safety and efficacy of a newly synthesized nanovectors in vitro represents, in fact, a necessary pre-requisite for in vivo experimentation: cultured cells are relatively simple experimental models that enable the analysis of the effects of nanocomposites under strictly controlled conditions, avoiding the complex systemic responses occurring in a living organism; moreover, in vitro experimentation is less expensive than in vivo tests, and allows a remarkable reduction of laboratory animals needed for the following systemic studies.

To design effective and safe administration procedures of nanovectors for therapeutic and diagnostic applications, it is obviously mandatory to assess their possible cytotoxicity after both short and long post-treatment times; in fact, cell necrosis or apoptosis may trigger an inflammatory response in tissues and organs of the patient receiving the 
nanoparticulate system (Rock and Kono, 2008; Kono et al., 2014). However, it is also essential to elucidate the uptake mechanism(s), the intracellular trafficking pathway, the interactions with cell organelles and the intracellular persistence of nanovectors, paying particular attention to their degradation route. The intracellular degradation pathway of nanoparticles (NPs) is crucial for estimating the efficacy of a nanocarrier since its entrapment into endosomes may imply a sequestration and a rapid inactivation of the loaded molecules by the lysosomal enzymes (Panyam et al., 2002).

Microscopy is especially suitable to describe the interaction of NPs with the cell surface and their intracellular fate following internalization. Fluorochrome-labelled NPs may be observed by conventional and confocal fluorescence microscopy, while the higher resolution of transmission electron microscopy allows to reveal the specific relationships of nanocomposites with the subcellular constituents.

Recently, we have also demonstrated that diaminobenzidine photo-oxidation (Maranto, 1982) is especially suitable for unambiguously visualizing fluorescently-labelled NPs at transmission electron microscopy (Malatesta et al., 2012; 2013b; 2014), thus allowing to overcome the limit due to the moderate electron density of many nanovectors (which makes them hardly distinguishable from the intracellular milieu), and to detect their remnants after lytic degradation.

The following chapters describe the information obtained by applying microscopical techniques to evaluate the suitability of different NPs for specific therapeutic and diagnostic purposes.

\section{CHITOSAN NANOPARTICLES FOR THE DELIVERY OF HYPOMETABOLIZING OPIOIDS}

D-Ala(2)-D-Leu(5)-enkephalin (DADLE) is a synthetic hypometabolizing opioid (Oeltgen et al., 1988) of potential biomedical interest (Malatesta et al., 2007). In fact, DADLE is able to significantly prolong the preservation of explanted organs (Oeltgen et al., 1996; Bolling et al., 1997; Su, 2000; Inuo et al., 2007; Tisherman et al., 2013), to improve cardioprotection (Romano et al., 2004; Yao et al., 2007; Forster et al., 2007; 2010) and neuroprotection (Borlongan et al., 2004; 2009; Su et al., 2007; Wang et al., 2011; Arrich et al., 2012) under ischemic conditions, and to act as anti-tumour agent (Fichna and Janecka, 2004; 
Debruyne et al., 2010; Tsai et al., 2010). Targeting DADLE to the brain would be instrumental to assess its hypometabolising effects in vivo with a consequent decrease in body temperature, which could improve the surgical procedures that imply hypothermy (such as in aortic arch surgery: Yan et al., 2013). The use in vivo of DADLE is, however, problematic since this molecule is degraded by plasmatic enkephalinases in a few minutes (Shibanoki et al., 1991) and cannot cross the blood brain barrier; encapsulating DADLE into NPs could make its systemic administration more efficient.

Chitosan is a natural cationic polysaccharide widely investigated for the development of drug delivery systems due to its peculiar features such as low immunogenicity and toxicity, easy functionalizability, availability, sustainability and biodegradability (Kumar et al., 2004; Hu et al., 2013; El Kadib et al., 2014; Luo and Wang, 2014). Chitosan NPs are considered as good carriers for the sustained intracellular delivery of specific molecules since they are able to protect the loaded drugs from lysosomal degradation (Koping-Hoggard et al., 2004; Douglas and Tabrizian, 2005; Serda et al., 2010; Zaki et al., 2011) and to cross diverse biological barriers (Schipper et al., 1997; Peppas and Huang, 2004), including the blood brain barrier (Karatas et al., 2009; Songjiang and Lixiang, 2009; Wang et al., 2010; Jaruszewski et al., 2012). These characteristics make chitosan NPs especially promising for DADLE delivery.

With this aim, we investigated the behavior of chitosan NPs inside cultured neuronal cells, and we monitored the intracellular drug release by DADLE-loaded NPs (Malatesta et al., 2012; 2013a). According to previous observations in other cell types (e.g. Huang et al., 2002; Ma and Lim, 2003; Harush-Frenkel et al., 2007; Park et al., 2010; Zaki et al., 2011), chitosan NPs proved to be efficiently internalized by endocytosis (Fig. 1a), to distribute in the cytoplasm accumulating in the perinuclear region (Fig. 1b), and to escape endosomal degradation as they occur free in the cytosol (Fig. 1c). However, many NPs were also found inside secondary lysosomes and residual bodies, demonstrating that they finally enter the lytic pathway (Fig. 1d). When loaded with DADLE, chitosan NPs efficiently release the opioid in the intracellular milieu inducing a fully reversible hypometabolic state which is significantly longer than that observed when DADLE had directly been administered as free molecules in the culture medium. Chitosan NPs were found to persist for weeks inside both the cytoplasm and nucleus (Malatesta et al., 2015); since their size does not 
allow them to pass through the nuclear pore complex (Allen et al., 2000; Labokha and Fassati, 2013), it is likely that they are entrapped into the nucleus at the end of mitosis, when the nuclear envelope reassembles (Guan et al., 2012). Although chitosan NPs were never found to make preferential contact with any nuclear component, they could interfere with the overall nuclear functions (e.g. by establishing electrostatic interactions with the nucleic acids, Lai and Lin, 2009). Therefore, despite the absence of cell death or damage up to two weeks after internalization, further investigation is mandatory on the possible long-term effects of chitosan NP.
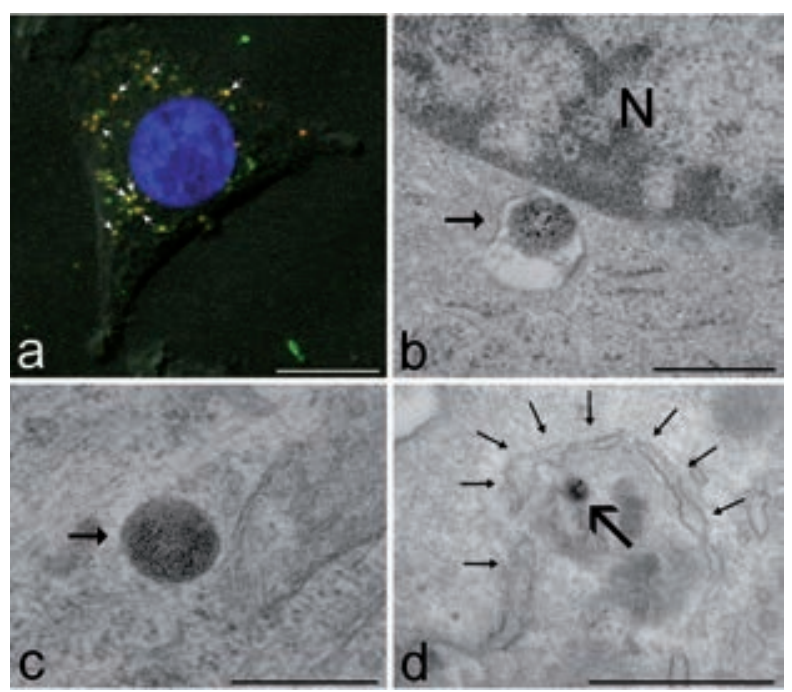

Fig. 1. a. Confocal micrograph of a cell after incubation with fluorescein 5(6)-isothiocyanate labelled chitosan NPs; the cells were previously incubated with the red-fluorescing dye, PKH26 to label the plasma membrane. For several NPs (arrows), green and red fluorescence co-locate, as the result of the endocytotic internalization of part of the plasma membrane. Bar, $10 \mu \mathrm{m} . b$-d. Transmission electron micrographs of cells incubated with chitosan NPs; the fine granular, dark reaction product of diaminobenzidine photo-oxidation makes the NPs clearly detectable. b) A NP enclosed in an endosome (arrow) is located very close to the nuclear envelope. $N$, nucleus. c) A NP (arrow) occurs free in the cytoplasm. d) A dual membrane (thin arrows) partially surrounds a NP (arrow). Bars, $500 \mathrm{~nm}$. (a-c, from Malatesta et al., 2012; d, from Malatesta et al., 2015). 
LIPOSOMES, POLYMERIC NANOPARTICLES AND MESOPOROUS SILICA NANOPARTICLES AS DRUG DELIVERY SYSTEMS FOR MUSCLE CELLS

Myotonic dystrophies (DM) are genetically heterogeneous neuromuscular disorders with autosomal dominant inheritance characterized by a variety of pathological features, especially concerning motor functions (Harper, 2001; Meola and Cardani, 2015). Currently, no disease-modifying therapies are available, and treatments are administered to only manage symptoms. Promising results have been obtained with experimental therapies based on either antisense oligomers or drugs such as pentamidine or actinomycin D (e.g. Lee et al., 2009; Warf et al., 2009; Wong et al., 2011; Childs-Disney et al., 2012; Lee et al., 2012; Parkesh et al., 2012; Wheeler et al., 2012; Coonrod et al., 2013; Nguyen et al., 2014; 2015; Pandey et al., 2015; Siboni et al., 2016). However, these molecules have scarce therapeutic applicability in humans because of their low bioavailability due to enzymatic degradation or their high systemic toxicity. Nanocarriers are able to protect the encapsulated agents from lysis and to allow its sustained release inside the cells: they may, therefore, represent a suitable approach to improve the administration of these therapeutic agents. The nanocarriers must obviously be biocompatible and biodegradable to safely play their action without damaging patient's organism, and this is especially important when they are aimed at delivering therapeutic agents to restore the normal physiological functions in diseased cells that are to be preserved (as the highly differentiated non-cycling cells of skeletal muscles, heart or the central nervous system).

In the attempt to set up an innovative therapeutic strategy based on biocompatible nanocarriers, we tested in cultured cells different biocompatible NPs already known to act as efficient drug-delivery systems. We focused on liposomes, mesoporous silica NPs and polymeric NPs.

Liposomes are attractive vehicles for drug delivery: they are composed of natural phospholipids, consequently being biologically inert and weakly immunogenic, and possess low intrinsic toxicity, high biocompatibility and biodegradability. Further, drugs with different lipophilicities can be encapsulated into liposomes: lipophilic drugs are entrapped in the lipid bilayer while hydrophilic drugs in the aqueous compartment, and the amphiphilic agents are encapsulated 
both in the lipid bilayer and in the aqueous core (Arpicco et al., 2013; Pedrini et al., 2014). In our study, we used unconjugated and hyaluronic-acid-conjugated liposomes in order to compare their internalization capability (it is known that hyaluronic acid may increase the uptake efficiency by cells bearing the CD44 receptors, Yu et al., 2013; Li et al., 2015).

Mesoporous silica NPs have attracted increasing attention due to their peculiar features: they can be easily synthesized and functionalized, show an excellent chemical stability, and are able to load large amounts of molecules whose release can be modulated by varying the size of the pores; moreover, they proved to be highly biocompatible (Chen et al., 2014; Sapino et al., 2015). Interestingly, both small molecules and oligonucleotides may be encapsulated in mesoporous silica NPs (Peng et al., 2006). In our study we used amino-mesoporous silica NPs.

Polymeric NPs are made of either natural or synthetic polymers that may be structured as nanospheres (where the loaded drugs are homogeneously dispersed in the matrix) and nanocapsules (where the drug is restricted to the aqueous or oily hollow enclosed in a thin polymeric layer) (Grottkau et al., 2013). Polymeric NPs are able to improve the solubility and stability of hydrophobic drugs thus reducing their toxicity; this allows a controlled and sustainable release at relatively low doses. Moreover, they demonstrated a high stability in plasma (Stella et al., 2000; 2007a; b; Lince et al., 2011). In our study we used poly(methoxypolyethyleneglycol cyanoacrylate-co-hexadecyl cyanoacrylate)-based polymeric NPs.

We first investigated the uptake and intracellular fate of the three nanocarrier types using a human cell line commonly used for basic research as a standardised in vitro system (HeLa cells) (Costanzo et al., 2016b). All nanocarriers were rapidly internalized by the cells, although the uptake mechanisms and intracellular distribution were characteristic of each nanovector type. Liposomes enter massively the cell, probably by fusion with the plasma membrane (Nazarenus et al., 2014) (although a receptor-mediated internalization cannot be excluded), and they undergo rapid degradation at the cell periphery (Fig. 2a).

Liposomic constituents diffuse into the cytosol and accumulate in lipidic droplets (Fig. 2a'), that are then extruded from the cell surface (a process likely due to excessive uptake of exogenous material). 
The rapid intracellular disaggregation of liposomes suggests that they may be suitable for carrying drugs to be rapidly and massively released.

Polymeric NPs enter the cell individually via endocytosis, and occur in the cytoplasm either inside vacuoles or free (Fig. 2b, b'), demonstrating their ability to escape endosomes. However, most of polymeric NPs re-enter the lytic pathway due to the autophagic process, thus undergoing enzymatic degradation in a few hours. The short intracellular permanence suggests the utilization of these NPs for rapid drug release.

Mesoporous silica NPs are internalized as large clusters via endocytosis and phagocytosis, and remain always enclosed in vacuoles (first endosomes, then secondary lysosomes and finally residual bodies), thus following the intracellular lytic route (Fig. 2c, c'). However, they persist for long time inside the cell, suggesting their utilization for sustained release of drugs able to cope with the enzymatic degradation and then cross the vacuole membrane.

Based on these promising results, we investigated the effect of these NPs in an established myoblast cell line (C2C12) (Costanzo, 2016a). In these myoblasts, liposomes and amine-mesoporous silica NPs showed similar results as in HeLa cells, but the cyanoacrylatebased polymeric NPs were found to induce a dramatic increase of cell death and damage.

This strongly suggests that the biological effects of a nanovector may strictly be related to the cell type. Cyanoacrylate-based polymeric NPs were then replaced by poly(lactic-co-glycolic acid) (PLGA) NPs, which proved to be safe (unpublished results). PLGA is, in fact, one of the most successfully used biodegradable polymers because its hydrolysis leads to metabolite monomers (lactic acid and glycolic acid) which are endogenous and easily metabolized via the Krebs cycle, thus leading to a minimal systemic toxicity. Consistently, PLGA is approved by the US FDA and the European Medicine Agency (EMA) in various drug delivery systems for humans (Danhier et al., 2012).

We are presently investigating liposomes, amine-mesoporous silica NPs and PLGA NPs on primary human myoblasts from skeletal muscle biopsies of healthy and dystrophic subjects, with very encouraging results. 

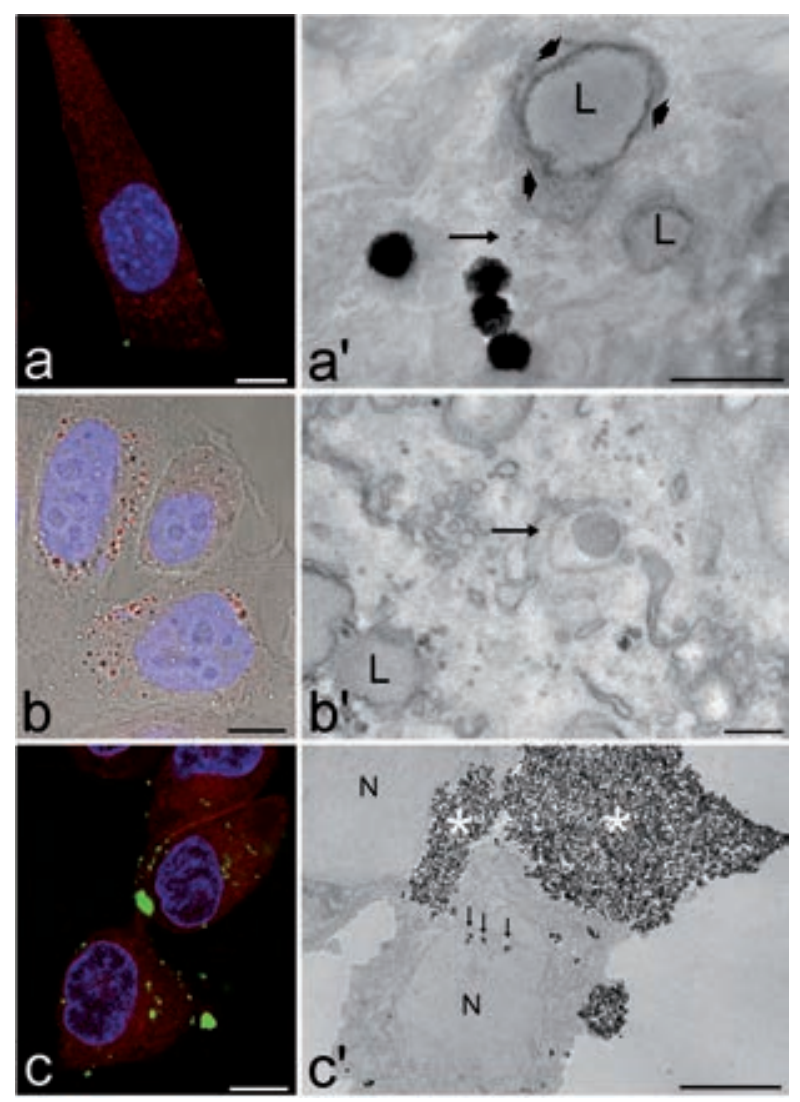

Fig. 2. a-c. Confocal micrographs of cells incubated with liposomes (green fluorescence, a), polymeric NPs (red fluorescence, b) and mesoporous silica NPs (green fluorescence, c). All the nanovectors are distributed in the cytoplasm but are absent from the nucleus; note the peripheral location of liposomes. DNA is stained with Hoechst 33342 (blue fluorescence). In $a$ and $c$ the cytoplasm is counterstained with trypan blue (red fluorescence); in b the red fluorescent signal of polymeric NPs has been merged with the brighfield image. Bars: $20 \mathrm{um}$. $a^{\prime}-c^{\prime}$. Transmission electron microscopy analysis of the intracellular distribution of liposomes $\left(a^{\prime}\right)$, polymeric NPs ( $\left.b^{\prime}\right)$ and mesoporous silica NPs $\left(c^{\prime}\right)$. $\left.a^{\prime}\right)$ Liposomes occur free in the cytoplasm and show a loose filamentous periphery. Electron dense fine granular material (arrow) occurs in the cytosol in close proximity to liposomes and lipid droplets $(L)$. Granular material appears distributed also at the periphery (arrowheads) of the lipid droplets (L). b') A polymeric NP is enclosed in an endosome (arrow). c') Large aggregates of mesoporous silica NPs occur at the cell surface (asterisks). Small clusters of NPs are visible inside the cytoplasm, even inside nuclear invaginations (arrows). N, nucleus. Bars, $500 \mathrm{~nm}\left(a^{\prime}, b^{\prime}\right) ; 5 \mu \mathrm{m}$ (c'). (from Costanzo et al., 2016a). 


\section{MANGANESE-CONTAINING NPS AS A NOVEL CONTRAST AGENT FOR MAGNETIC RESONANCE IMAGING}

Magnetic resonance imaging (MRI) is powerful diagnostic technique that exploits the properties of atom nuclei inside a living body (Cleary and Peters, 2010). It is a current non-invasive tool in daily clinics, allowing diagnosis to be performed in real time. An intrinsic limitation of MRI is its low sensitivity, which often compromises diagnostic quality. To overcome this disadvantage, different types of contrast agents, which are effective in shortening relaxation times of nearby protons, have been developed and used (Chopra et al., 2012); among them, gadolinium $(\mathrm{Gd})$ is currently used in the clinics as MRI contrast agent. Gd-based agents must always be used in chelated form due to the high toxicity of free Gd, although they are not completely free of serious risk (e.g., nephrogenic systemic fibrosis may be induced; Kaewlai and Abujudeh, 2012). A promising alternative to $\mathrm{Gd}$ is represented by manganese $(\mathrm{Mn})$ and its derivatives.

$\mathrm{Mn}$ is a trace element physiologically present in the human organism since it is indispensable for several metabolic pathways (e.g., blood coagulation and hemostasis, blood glucose regulation, bone growth, nervous tissue function) (Wedler and Denman, 1984; Patchett et al., 1991; Zwingmann et al., 2004; Miao and St Clair, 2009; Horning et al., 2015). $\mathrm{Mn}^{2+}$ is characterized by paramagnetic properties that cause a reduction in T1 relaxation times of water resulting in positive contrast enhancement i.e., a 'bright' signal in T1-weighted MRI images of tissues where $\mathrm{Mn}^{2+}$ has accumulated. Accordingly, many $\mathrm{Mn}$ complexes have been investigated as alternative contrast agents for MRI (Mendonça-Dias et al., 1983; Fornasiero et al., 1987; Nordhoy et al., 2004; Lelyveld et al., 2011). Further, commercial Mnbased MRI contrast agents have been developed such as, mangafodipir trisodium (Mn-DPDP). However, Mn-based complexes easily dissociate after administration with the formation of free $\mathrm{Mn}^{2+}$; exposure to excess $\mathrm{Mn}$ is neurotoxic, and $\mathrm{Mn}^{2+}$ accumulates most notably in the striatum resulting in the $\mathrm{Mn}$ poisoning referred to as 'manganism' (Santamaria, 2008). This suggests the need for biocompatible and thermodynamically stable Mn compounds.

Thanks to the progress in nanotechnology, Mn can be encapsulated in different types of NPs made of biocompatible materials which are expected to both limit Mn toxicity and become potential positive 
contrast agents for T1-weighted MRI ( $\mathrm{Na}$ et al., 2007; Shin et al., 2009; Howell et al., 2013; Lee et al., 2014). However, the research on Mn-based nano-contrast agents is still at a relatively early stage, and there is a paucity of investigations on in vivo and in vitro toxicity of Mn-based NPs (Li et al., 2013; Xiao et al., 2013; Bellusci et al., 2014; Katsnelson et al., 2015; Yu et al., 2015).

Our group focused on NPs obtained by thermal decomposition of Mn-oleate complex and then encapsulated in a phospholipidic shell containing also a small amount of polyethylene glycol, thus improving their water solubility, stability, bioavailability and biocompatibility. These NPs are especially interesting since they gave promising results as MRI contrast agents and drug carriers (Howell et al., 2013). By combining flow cytometry, confocal microscopy and transmission electron microscopy, we explored in vitro their cytotoxicity, internalization kinetics, intracellular distribution and degradation (Costanzo et al., 2016c).

Our results confirmed the safety of these Mn-containing NPs since the viability assay did not detect alterations after both short (one hour) and long (two days) incubation times. Flow cytometry allowed monitoring the internalization kinetics of NPs: they entered the cells in a few minutes and reached the maximum internalization after one hour exposure, thus demonstrating an excellent uptake efficiency. Fluorescence microscopy and transmission electron microscopy demonstrated that Mn-containing NPs enter the cell probably by fusion with the plasma membrane (Fig. $3 a, b)$, and remain free in the cytosol, without making contact with cell organelles (Fig. 3c). It is in fact known that the uptake of hydrophobic nanocomposites may occur by lipid raft-mediated endocytosis, a process that allows to bypass the endolytic pathway thus facilitating the intracellular permanence of the NPs (Lanza et al., 2011). Interestingly, lipid rafts are typical of numerous tumor cells (Mollinedo and Gajate, 2015; Nicolson, 2015), thus opening promising perspectives for the use of Mn-containing NPs for diagnostic and therapeutic purposes.

Despite the long intracellular permanence of free Mn-containing NPs, no structural damage of cell components was detected, suggesting that the organic shell is not degraded by the cytosolic enzymes. Finally, the Mn-containing NPs undergo autophagic process, thus entering the lysosomal route and being degraded through a physiological pathway. The long-lasting intracellular per- 
manence of Mn-containing NPs must be taken into account as a potential risk in the case of multiple administrations as contrast agent, but it may represent an advantage for their use as drug delivery system since it may ensure a sustained release.

Taken together, our in vitro data suggest that Mn-containing NPs may be promisingly considered for therapeutic and diagnostic applications in vivo, as drug carriers or contrast agent for MRI.

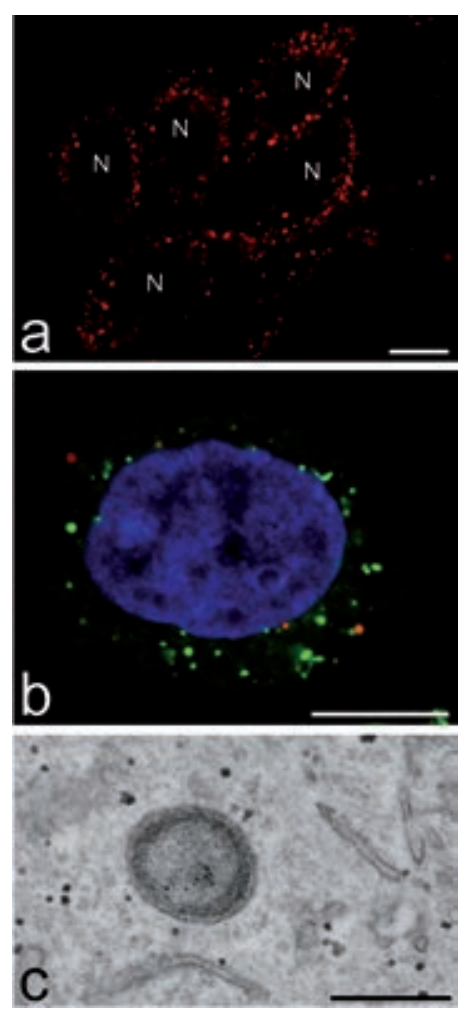

Fig. 3. a,b. Confocal fluorescence microscopy. a) Red fluorescent $\mathrm{MnO}$ containing-NPs are distributed in the whole cytoplasm, especially in the perinuclear region, but are absent from nuclei (N). b) Cells pre-incubated with the PKH67 green-fluorescing dye to label the plasma membrane and endocytotic vesicles: the red fluorescing NPs never co-locate with green fluorescent endosomes. DNA is stained with Hoechst 33258 (blue fluorescence). Bars, $10 \mu m$.c. Transmission electron micrograph of a $\mathrm{MnO}$ containing NPs showing the fine electron dense granular reaction product of diaminobenzidine photo-oxidation. Bar, $500 \mathrm{~nm}$. 


\section{CONCLUSIONS}

Microscopical techniques proved to be a powerful approach to investigate in vitro the effects of nanovectors on cell components. By brightfield and fluorescence microscopy, the uptake and distribution of NPs in the whole cell population may be described, while transmission electron microscopy provides highly-resolved images of the NP interaction with the plasma membrane and the subcellular organelles, and of the induced ultrastructural cell damage undetectable at light microscopy. Microscopical analyses are not limited to morphological observation, since the NPs can be detected in association with single molecular components visualized by cytochemical staining or immunocytochemical labelling.

It may be envisaged that this approach in situ will be increasingly applied to precisely elucidate the spatial and functional relationships of nanovectors with specific cell constituents in the attempt to fully understand the interaction mechanisms and the potential risks of NP administration.

\section{ACKNOWLEDGEMENTS}

We thank Prof. S. Arpicco for kindly providing us with a confocal image of $\mathrm{MnO}$ containing nanoparticles. F.C. is a $\mathrm{PhD}$ student in receipt of fellowships from the Doctoral Program in "Nanoscience and advanced technologies" of the University of Verona.

\section{REFERENCES}

Allen TD, Cronshaw JM, Bagley S, Kiseleva E, Goldberg MW. The nuclear pore complex: mediator of translocation between nucleus and cytoplasm. J Cell Sci 2000;113:1651-9.

Arpicco S, Lerda C, Dalla Pozza E, Costanzo C, Tsapis N, Stella B, et al. Hyaluronic acid-coated liposomes for active targeting of gemcitabine. Eur J Pharm Biopharm 2013;85:373-80.

Arrich J, Holzer M, Havel C, Müllner M, Herkner H. Hypothermia for neuroprotection in adults after cardiopulmonary resuscitation. Cochrane Database Syst Rev 2012;9:CD004128.

Bellusci M, La Barbera A, Padella F, Mancuso M, Pasquo A, Grollino MG, et al. Biodistribution and acute toxicity of a nanofluid containing manganese iron oxide 
nanoparticles produced by a mechanochemical process. Int J Nanomedicine 2014;9:1919-29.

Bolling SF, Su TP, Childs KF, Ning XH, Horton N, Kilgore K, et al. The use of hibernation induction triggers for cardiac transplant preservation. Transplantation 1997;63:326-9.

Borlongan CV, Hayashi T, Oeltgen PR, Su TP, Wang Y. Hibernation-like state induced by an opioid peptide protects against experimental stroke. BMC Biol 2009;7:31.

Borlongan CV, Wang Y, Su TP. Delta opioid peptide (D-Ala 2, D-Leu 5) enkephalin: linking bibernation and neuroprotection. Front Biosci 2004;9:3392-8.

Chen Y, Chen H, Shi J. Drug delivery/imaging multifunctionality of mesoporous silicabased composite nanostructures. Expert Opin Drug Deliv 2014;11:917-30.

Childs-Disney JL, Hoskins J, Rzuczek SG, Thornton CA, Disney MD. Rationally designed small molecules targeting the RNA that causes myotonic dystrophy type 1 are potently bioactive. ACS ChemBiol 2012;7:856-62.

Chopra A, Shan L, Eckelman WC, Leung K, Latterner M, Bryant SH, et al. Molecular Imaging and Contrast Agent Database (MICAD): evolution and progress. Mol Imaging Biol 2012;14:4-13.

Cleary K, Peters TM. Image-guided interventions: technology review and clinical applications. Annu Rev Biomed Eng 2010;12:119-42.

Coonrod LA, Nakamori M, Wang W, Carrell S, Hilton CL, Bodner MJ, et al. Reducing levels of toxic RNA with small molecules. ACS ChemBiol 2013;8:2528-37.

Costanzo M. Pilot studies for the treatment of sarcopenia and myotonic dystrophy: a multimodal approach. 2016a. PhD thesis.

Costanzo M, Carton F, Marengo A, Berlier G, Stella B, Arpicco S, et al. Fluorescence and electron microscopy to visualize the intracellular fate of nanoparticles for drug delivery. Eur J Histochem 2016b;60:2640.

Costanzo M, Scolaro L, Berlier G, Marengo A, Grecchi S, Zancanaro C, et al. Cell uptake and intracellular fate of phospholipidic manganese-based nanoparticles. Int J Pharm 2016c;508:83-91.

Danhier F, Ansorena E, Silva JM, Coco R, Le Breton A, Préat V. PLGA-based nanoparticles: An overview of biomedical applications. J Control Release 2012;161:505-22.

Debruyne D, Leroy A, De Wever O, Vakaet L, Mareel M, Bracke M. Direct effects of delta opioid receptor agonists on invasion-associated activities of HCT-8/E11 colon cancer cells. Anticancer Res 2010;30:9-18.

Douglas KL, Tabrizian M. Effect of experimental parameters on the formation of alginate-chitosan nanoparticles and evaluation of their potential application as DNA carrier. J Biomater Sci Polym Ed 2005;16:43-56.

El Kadib A, Bousmina M, Brunel D. Recent progress in chitosan bio-based soft nanomaterials. J Nanosci Nanotechnol 2014;14:308-31.

Fichna J, Janecka A. Opioid peptides in cancer. Cancer Metastasis Rev 2004;23:351-66.

Fornasiero D, Bellen JC, Baker RJ, Chatterton BE. Paramagnetic complexes of manganese(II), iron(III), and gadolinium(III) as contrast agents for magnetic resonance imaging. The influence of stability constants on the biodistribution of radioactive aminopolycarboxylate complexes. Invest Radiol 1987;22:322-7. 
Förster K, Kuno A, Solenkova N, Felix SB, Krieg T. The delta-opioid receptor agonist DADLE at reperfusion protects the heart through activation of pro-survival kinases via EGF receptor transactivation. Am J Physiol Heart Circ Physiol 2007;293: H1604-8.

Förster K, Richter H, Alexeyev MF, Rosskopf D, Felix SB, Krieg T. Inbibition of glycogen synthase kinase 3 beta prevents peroxide-induced collapse of mitochondrial membrane potential in rat ventricular myocytes. Clin Exp Pharmacol Physiol 2010;37:684-8.

Grottkau BE, Cai X, Wang J, Yang X, Lin Y. Polymeric nanoparticles for a drug delivery system. Curr Drug Metab 2013;14:840-6.

Guan M, Zhu Q, Liu Y, Bei Y-Y, Gu Z-L, Zhang X-N, et al. Uptake and transport of a novel anticancer drug-delivery system: lactosyl-norcantharidin-associated $\mathrm{N}$ trimethyl chitosan nanoparticles across intestinal Caco-2 cell monolayers. Int J Nanomedicine 2012;7:1921-30.

Harper PS. Myotonic Dystrophy. London: WB Saunders 2001.

Harush-Frenkel O, Debotton N, Benita S, Altschuler Y. Targeting of nanoparticles to the clathrin-mediated endocytic pathway. Biochem Biophys Res Commun 2007;353:26-32.

Horning KJ, Caito SW, Tipps KG, Bowman AB, Aschner M. Manganese is essential for neuronal health. Annu Rev Nutr 2015;35:71-108.

Howell M, Mallela MJ, Wang C, Ravi S, Dixit S, Garapati U, et al. Manganese-loaded lipid-micellar theranostics for simultaneous drug and gene delivery to lungs. J Control Release 2013;167:210-8.

$\mathrm{Hu}$ L, Sun Y, Wu Y. Advances in chitosan-based drug delivery vebicles. Nanoscale 2013;5:3103-11.

Huang M, Ma Z, Khor E, Lim L-Y. Uptake of FITC-chitosan nanoparticles by A549 cells. Pharm Res 2002;19:1488-94.

Inuo H, Eguchi S, Yanaga K, Hamada T, Yamanouchi K, Okudaira S, et al. Protective effects of a bibernation-inducer on bepatocyte injury induced by bypothermic preservation. J Hepatobiliary Pancreat Surg 2007;14:509-13.

Jaruszewski KM, Ramakrishnan S, Poduslo JF, Kandimalla KK. Chitosan enbances the stability and targeting of immuno-nanovebicles to cerebro-vascular deposits of Alzheimer's disease amyloid protein. Nanomedicine 2012;8:250-60.

Kaewlai R, Abujudeh H. Nephrogenic systemic fibrosis. AJR Am J Roentgenol 2012;199: W17-23.

Karatas H, Aktas Y, Gursoy-Ozdemir Y, Bodur E, Yemisci M, Caban S, et al. A nanomedicine transports a peptide caspase-3 inbibitor across the blood-brain barrier and provides neuroprotection. J Neurosci 2009;29:13761-9.

Katsnelson BA, Minigaliyeva IA, Panov VG, Privalova LI, Varaksin AN, Gurvich VB, et al. Some patterns of metallic nanoparticles' combined subchronic toxicity as exemplified by a combination of nickel and manganese oxide nanoparticles. Food Chem Toxicol 2015;86:351-64.

Kono H, Kimura Y, Latz, E. Inflammasome activation in response to dead cells and their metabolites. Curr Opin Immunol 2014;30:91-8. 
Koping-Hoggard M, Varum KM, Issa M, Danielsen S, Christensen BE, Stokke BT, et al. Improved chitosan-mediated gene delivery based on easily dissociated chitosan polyplexes of highly defined chitosan oligomers. Gene Ther 2004;11:1441-52.

Kumar MNVR, Muzzarelli RAA, Muzzarelli C, Sashiwa H, Domb AJ. Chitosan chemistry and pharmaceutical perspectives. Chem Rev 2004;104:6017-84.

Labokha AA, Fassati A. Viruses challenge selectivity barrier of nuclear pores. Viruses 2013;5:2410-23.

Lai WF, Lin MC. Nucleic acid delivery with chitosan and its derivatives. J Control Release 2009;134:158-68.

Lanza R, Langer R, Vacanti JP. Principles of tissue engineering. New York: Academic Press 2011.

Lee JE, Bennett CF, Cooper TA. RNase H-mediated degradation of toxic RNA in myotonic dystrophy type 1. Proc Natl Acad Sci U S A 2012;109:4221-6.

Lee MM, Pushechnikov A, Disney MD. Rational and modular design of potent ligands targeting the RNA that causes myotonic dystropby 2. ACS Chem Biol 2009;4:345-55.

Lee SH, Kim BH, Na HB, Hyeon T. Paramagnetic inorganic nanoparticles as T-1 MRI contrast agents. WIRES Nanomed Nanobi 2014;6:196-209.

Lelyveld VS, Brustad E, Arnold FH, Jasanoff A. Metal-substituted protein MRI contrast agents engineered for enbanced relaxivity and ligand sensitivity. J Am Chem Soc 2011;133:649-51.

Li J, Hu Y, Yang J, Wei P, Sun W, Shen M, et al. Hyaluronic acid-modified Fe3O4@Au core/shell nanostars for multimodal imaging and photothermal therapy of tumors. Biomaterials 2015;38:10-21.

Li J, Zhao Z, Feng J, Gao J, Chen Z. Understanding the metabolic fate and assessing the biosafety of $\mathrm{MnO}$ nanoparticles by metabonomic analysis. Nanotechnology 2013;24:455102.

Lince F, Bolognesi S, Stella B, Marchisio DL, Dosio F. Preparation of polymer nanoparticles loaded with doxorubicin for controlled drug delivery. Chem Eng Res Des 2011;89:2410-9.

Luo Y, Wang Q. Recent development of chitosan-based polyelectrolyte complexes with natural polysaccharides for drug delivery. Int J Biol Macromol 2014;64:353-67.

Ma Z, Lim L-Y. Uptake of chitosan and associated insulin in Caco-2 cell monolayers: a comparison between chitosan molecules and chitosan nanoparticles. Pharm Res 2003;20:1812-9.

Malatesta M, Biggiogera M, Zancanaro C. Hypometabolic induced state: a potential tool in biomedicine and space exploration. Rev Environ Sci Biotechnol 2007;6:47-60.

Malatesta M, Galimberti V, Cisterna B, Costanzo M, Biggiogera M, Zancanaro C. Chitosan nanoparticles are efficient carriers for delivering biodegradable drugs to neuronal cells. Histochem Cell Biol 2013a;141:551-8.

Malatesta M, Giagnacovo M, Costanzo M, Conti B, Genta I, Dorati R, et al. Diaminobenzidine photoconversion is a suitable tool for tracking the intracellular location of fluorescently labelled nanoparticles at transmission electron microscopy. Eur J Histochem 2012;56:e20.

Malatesta M, Grecchi S, Chiesa E, Cisterna B, Costanzo M, Zancanaro C. Internalized 
chitosan nanoparticles persist for long time in cultured cells. Eur J Histochem 2015;59:2492.

Malatesta M, Pellicciari C, Cisterna B, Costanzo M, Galimberti V, Biggiogera M, et al. Tracing nanoparticles and photosensitizing molecules at transmission electron microscopy by diaminobenzidine photo-oxidation. Micron 2014;59C:44-51.

Malatesta M, Zancanaro C, Costanzo M, Cisterna B, Pellicciari C. Simultaneous ultrastructural analysis of fluorochrome-photoconverted diaminobenzidine and gold immunolabelling in cultured cells. Eur J Histochem 2013b;57:e26.

Maranto AR. Neuronal mapping: a photooxidation reaction makes Lucifer yellow useful for electron microscopy. Science 1982;217:953-5.

Mendonça-Dias MH, Gaggelli E, Lauterbur PC. Paramagnetic contrast agents in nuclear magnetic resonance medical imaging. Semin Nucl Med 1983;13:364-76.

Meola G, Cardani R. Myotonic dystrophies: An update on clinical aspects, genetic, pathology, and molecular pathomechanisms. Biochim Biophys Acta 2015;1852:594-606.

Miao L, St Clair DK. Regulation of superoxide dismutase genes: implications in disease. Free Radical Bio Med 2009;47:344-56.

Mollinedo F, Gajate C. Lipid rafts as major platforms for signaling regulation in cancer. Adv Biol Regul 2015;57:130-46.

Na HB, Lee J, An HK, Park YI, Park M, Lee IS, et al. Development of a T1 contrast agent for magnetic resonance imaging using $\mathrm{MnO}$ nanoparticles. Angew Chem Int Ed Engl 2007;46:5397-5401.

Nazarenus M, Zhang Q, Soliman MG, del Pino P, Pelaz B, Carregal-Romero S, et al. In vitro interaction of colloidal nanoparticles with mammalian cells: What have we learned thus far? Beilstein J Nanotechnol 2014;5:1477-90.

Nguyen L, Lee JY, Wong CH, Zimmerman SC. Small Molecules that Target the Toxic RNA in Myotonic Dystrophy Type 2. Chem Med Chem 2014;9:2455-62.

Nguyen L, Luu LM, Peng S, Serrano JF, Edwin Chan HY, Zimmerman SC. Rationally designed small molecules that target both the dna and rna causing myotonic dystrophy type 1. J Am Chem Soc 2015;137:14180-9.

Nicolson GL. Cell membrane fluid-mosaic structure and cancer metastasis. Cancer Res 2015;75:1169-76.

Nordhoy W, Anthonsen HW, Bruvold M, Brurok H, Skarra S, Krane J, et al. Intracellular manganese ions provide strong $T 1$ relaxation in rat myocardium. Magn Reson Med 2004;52:506-14.

Oeltgen PR, Horton ND, Bolling SF, Su TP. Extended lung preservation with the use of bibernation trigger factors. Ann Thorac Surg 1996;61:1488-93.

Oeltgen PR, Nilekani WA, Nuchols PA, Spurrier WA, Su TP. Further studies on opioids and hibernation: delta opioid receptor ligand selectively induced bibernation in summer active ground squirrels. Life Sci 1988;43:1565-74.

Pandey SK, Wheeler TM, Justice SL, Kim A, Younis HS, Gattis D, et al. Identification and characterization of modified antisense oligonucleotides targeting DMPK in mice and nonbuman primates for the treatment of myotonic dystrophy type 1. J Pharmacol Exp Ther 2015;355:329-40.

Panyam J, Zhou WZ, Prabha S, Sahoo SK, Labhasetwar V. Rapid endolysosomal escape 
of poly(DL-lactide-coglycolide) nanoparticles: implications for drug and gene delivery. FASEB J 2002;16:1217-26.

Park S, Lee SJ, Chung H, Her S, Choi Y, Kim K, et al. Cellular uptake patbway and drug release characteristics of drug-encapsulated glycol chitosan nanoparticles in live cells. Microsc Res Tech 2010;73:857-65.

Parkesh R, Childs-Disney JL, Nakamori M, Kumar A, Wang E, Wang T, et al. Design of a bioactive small molecule that targets the myotonic dystrophy type 1 RNA via an RNA motif-ligand database and chemical similarity searching. J Am Chem Soc 2012;134:4731-42.

Patchett ML, Daniel RM, Morgan HW. Characterisation of arginase from the extreme thermophile Bacillus caldovelox. Biochim Biophys Acta 1991;1077:291-8.

Pedrini I, Gazzano E, Chegaev K, Rolando B, Marengo A, Kopecka J, et al. Liposomal nitrooxy-doxorubicin: one step over Caelyx ${ }^{\circledR}$ in drug-resistant buman cancer cells. Mol Pharm 2014;11:3068-79.

Peng J, He X, Wang K, Tan W, Li H, Xing X, et al. An antisense oligonucleotide carrier based on amino silica nanoparticles for antisense inbibition of cancer cells. Nanomedicine 2006;2:113-20.

Peppas NA, Huang Y. Nanoscale technology of mucoadhesive interactions. Adv Drug Deliv Rev 2004;56:1675-87.

Rock KL, Kono H. The inflammatory response to cell death. Annu. Rev. Pathol. 2008:3:99-126.

Romano MA, McNish R, Seymour EM, Traynor JR, Bolling SF. Differential effects of opioid peptides on myocardial ischemic tolerance. J Surg Res 2004;119:46-50.

Santamaria AB. Manganese exposure, essentiality and toxicity. Indian J Med Res 2008;128:484-500.

Sapino S, Ugazio E, Gastaldi L, Miletto I, Berlier G, Zonari D, et al. Mesoporous silica as topical nanocarriers for quercetin: characterization and in vitro studies. Eur J Pharm Biopharm 2015;89:116-25.

Schipper NGM, Olsson S, Hoogstraate JA, deBoer AG, Varum KM, Artursson P. Chitosans as absorption enbancers for poorly absorbable drugs 2: mechanism of absorption enbancement. Pharm Res 1997;14:923-9.

Serda RE, Mack A, van de Ven AL, Ferrati S, Dunner K Jr, Godin B, et al. Logic-embedded vectors for intracellular partitioning, endosomal escape, and exocytosis of nanoparticles. Small 2010;6:2691-700.

Shibanoki S, Weinberger SB, Beniston D, Nudelman KA, Schulteis G, Bennett EL, et al. Hydrolysis of [Leu] enkephalin by chick plasma in vitro. J Pharmacol Exp Ther 1991;256:650-5.

Shin J, Anisur RM, Ko MK, Im GH, Lee JH, Lee IS. Hollow manganese oxide nanoparticles as multifunctional agents for magnetic resonance imaging and drug delivery. Angew Chem Int Ed Engl 2009;48:321-4.

Siboni RB, Nakamori M, Wagner SD, Daniel MC, Matthew KT, Berglund JA. Actinomycin D specifically reduces expanded CUG repeat $R N A$ in myotonic dystrophy models. Cell Rep 2015;13:2386-94.

Songjiang Z, Lixiang W. Amyloid-Beta associated with chitosan nano-carrier has favor- 
able immunogenicity and permeates the BBB. AAPS PharmSciTech 2009; 10:900-5.

Stella B, Arpicco S, Peracchia MT, Desmaële D, Hoebeke J, Renoir JM, et al. Design of folic acid-conjugated nanoparticles for drug targeting. J Pharm Sci 2000;89:1452-64.

Stella B, Arpicco S, Rocco F, Marsaud V, Renoir JM, Cattel L, et al. Encapsulation of gemcitabine lipophilic derivatives into polycyanoacrylate nanospheres and nanocapsules. Int J Pharm 2007a;344:71-7.

Stella B, Marsaud V, Arpicco S, Géraud G, Cattel L, Couvreur P, et al. Biological characterization of folic acid-conjugated poly(H2NPEGCA-co-HDCA) nanoparticles in cellular models. J Drug Target 2007b;15:146-53.

Su DS, Wang ZH, Zheng YJ, Zhao YH, Wang XR. Dose-dependent neuroprotection of delta opioid peptide [D-Ala2, D-Leu5] enkephalin in neuronal death and retarded behavior induced by forebrain ischemia in rats. Neurosci Lett 2007;423:113-7.

$\mathrm{Su}$ TP. Delta opioid peptide[D-Ala(2),D-Leu(5)]enkephalin promotes cell survival. J Biomed Sci 2000;7:195-9.

Tisherman SA (Moderator); Ornato JP, Peberdy MN, Tisherman SA (Participants). Managing bypothermia during organ transplantation and cardiac arrest. Ther Hypothermia Temp Manag 2013;3:7-10.

Tsai SY, Lee CT, Hayashi T, Freed WJ, Su TP. Delta opioid peptide DADLE and naltrexone cause cell cycle arrest and differentiation in a CNS neural progenitor cell line. Synapse 2010;64:267-73.

Wang S, Duan Y, Su D, Li W, Tan J, Yang D, et al. Delta opioid peptide [d-Ala2, d-Leu5] enkephalin (DADLE) triggers postconditioning against transient forebrain ischemia. Eur J Pharmacol 2011;658:140-4.

Wang ZH, Wang ZY, Sun CS, Wang CY, Jiang TY, Wang SL. Trimethylated chitosanconjugated PLGA nanoparticles for the delivery of drugs to the brain. Biomaterials 2010;31:908-15.

Warf MB, Nakamori M, Matthys CM, Thornton CA, Berglund JA. Pentamidine reverses the splicing defects associated with myotonic dystrophy. Proc Natl Acad Sci USA 2009;106:18551-6.

Wedler FC, Denman RB. Glutamine synthetase: the major Mn(II) enzyme in mammalian brain. Curr Top Cell Regul 1984;24:153-69.

Wheeler TM, Leger AJ, Pandey SK, MacLeod AR, Nakamori M, Cheng SH, et al. Targeting nuclear RNA for in vivo correction of myotonic dystrophy. Nature 2012;488:111-5.

Wong CH, Fu Y, Ramisetty SR, Baranger AM, Zimmerman SC. Selective inbibition of MBNL1-CCUG interaction by small molecules toward potential therapeutic agents for myotonic dystrophy type 2 (DM2). Nucleic Acids Res 2011;39:8881-90.

Xiao J, Tian XM, Yang C, Liu P, Luo NQ, Liang Y, et al. Ultrabigh relaxivity and safe probes of manganese oxide nanoparticles for in vivo imaging. Sci Rep 2013; $3: 3424$.

Yan TD, Bannon PG, Bavaria J, Coselli JS, Elefteriades JA, Griepp RB, et al. Consensus on bypothermia in aortic arch surgery. Ann Cardiothorac Surg 2013;2:163-8.

Yao LL, Wang YG, Cai WJ, Yao T, Zhu YC. Survivin mediates the anti-apoptotic effect 
of delta-opioid receptor stimulation in cardiomyocytes. J Cell Sci 2007;120(Pt 5):895-907.

Yu C, Zhou Z, Wang J, Sun J, Liu W, Sun Y, et al. In depth analysis of apoptosis induced by silica coated manganese oxide nanoparticles in vitro. J Hazard Mater 2015; 283:519-28.

Yu M, Jambhrunkar S, Thorn P, Chen J, Gu W, Yu C. Hyaluronic acid modified mesoporous silica nanoparticles for target drug delivery to CD44-overexpressing cancer cells. Nanoscale 2013;5:178-83.

Zaki NM, Nasti A, Tirelli N. Nanocarriers for cytoplasmic delivery: cellular uptake and intracellular fate of chitosan and byaluronic acid-coated chitosan nanoparticles in a phagocytic cell model. Macromol Biosci 2011;11:1747-60.

Zwingmann C, Leibfritz D, Hazell AS. Brain energy metabolism in a sub-acute rat model of manganese neurotoxicity: an ex vivo nuclear magnetic resonance study using [113C]glucose. Neurotoxicology 2004;25:573-87. 